\title{
Design Optimization of Double Plane Blade Ceiling Fan
}

\author{
Dr. Nitin K. Mandavgade ${ }^{1}$, Vikas Wakpanjar ${ }^{2}$ \\ ${ }^{1}$ Associate Professor \& Head of Department, ${ }^{2}$ UG Students \\ Department of Mechanical Engineering, Nagpur Institute of Technology \\ Mahurzari, Katol Road Nagpur (India)
}

DOI: 10.46335/IJIES.2020.5.8.3

\begin{abstract}
This study pertains to design optimization and arrangements of ceiling fan blade as a double plane blade ceiling fan to enhance air circulation, air velocity with energy efficiency. The sweep angle of the double blade profile is nonlinear. The design of experiment (DOE) and response surface method (RSM) methods were used in parallel to find the optimal arrangements of ceiling fan blades. The design variables considered were inboard angle of attack, outboard angle of attack, blade sweep, and stagger between the upper and lower blade. Numerical simulations were conducted using steady state Reynolds-averaged Nervier-Stokes (RANS) equations and the Spalart-Allmaras turbulence model.

The 12 cases were considered and base line result was validated through experimental data. Subsequently, the DOE method was employed to generate the blade design which reduces the number of simulations without losing the influence of different geometric parameter interactions. The response variables studied were volume flow rate, mass flow rate, torque, and energy efficiency. The optimal blade design and arrangements was identified using experimental conducted.
\end{abstract}

\section{INTRODUCTION}

$\mathbf{T}_{\mathrm{h}}$ he ceiling fan which provides the high air flow rate with low consumption of electric energy is the best one. The energy efficiency of ceiling fan in the household equipment can reshape urban living. Ceiling fans are widely used intropical regions for indoor comfort. Sathaye and Phadke et al. (2012) conducted cost-benefit analysis to establish the need of developing energy efficient ceiling fan technology for India, China and US. The energy efficiency is conceptualized in terms of less power consumption and associated carbon emissions. The study estimates that integration of existingtechnologies can improve the energy efficiency of ceiling fans by fifty percent. If by 2020 ceiling fan centric technologies are improved, this will translate into power savings of 70 tera Watt Hours per Year.

Ankur and Rochan et al. (2004) experimentally investigated the flow field of a ceiling fan. They used Smoke visualization and vane anemometers for visualization and flow velocity measurements respectively. The maximum recorded velocity is between 2 and $3 \mathrm{~m} / \mathrm{s}$ below the ceiling fan disk. Feasibility about using winglets at blade-tips was also 
assessed. Parker and Challahan et al. (2000) made an effort to find a design which had maximum air flow, uniform air movement and minimum acoustic signature in the room. Out of three different designs considered, tapered blades performed best.

The associated reduction of carbon dioxide emissions will be 25 million metric tons per year. Scholarly efforts are required for design, development and integration of energy-efficient ceiling fan technology. A great deal of interest has already emerged during the last several years for energy efficient ceiling fans. Bladeless fan studies of Jafari and Afshin et al. (2015) are one such example that haspulled attention of technology protagonists.

Experimental studies by Chiang and Pan et al. (2007),Falahat (2011) and Bhortake and Lachure et al.(2014) , theyhave concentrated on improving aerodynamic performance of ceiling fan, by carrying out blade design refinement. Bhortake and Lachure et al.(2014) used Response Surface Methodology (RSM) and generated design space with three fan blades, three down rod lengths, three room sizes and three fan rotation speeds. Falahat (2011) found optimal revolutions and angle of attack of a flat blade ceiling fan in a room. The effect of number of blades on aerodynamic efficiency was also investigated. The results concluded that a fan with four blades basedon a specific design results in maximum air circulation in the room. The flow behavior for a fan did not change excessively with four, five and six blades. The only penalization with the increase in number of blades was on energy consumption. Parker and Challahan et al. (2000) reported that ceiling fans used in combination with higher thermostat of airconditioning results in significant energy consumption savings.

Schiavon and Melikov (2008) investigate cooling effects with improved air circulation and report reduction in electricity from 10 to 28 percent. Schmdit and Patterson (2001) studied high efficiency tropical ceiling fan and conventional fan. A comparative study is done between approximate volume flow rate, mechanical power and electrical input power on the shaft. The new design saves electricity almost by a factor of two.

Azim (2014) developed a mathematical expression for axial velocity distribution of a ceiling fan. This mathematical formulation is in good agreement with computational and mathematical data of velocity field of ceiling fans.

Ramadan andNadar (2011) derived a mathematical formula which is helpful to find the velocity of the fan above the ground floor in a defined space. The study reports that maximum tangential velocity is at the blade tip and it decreases as the air moves downward. Moreover, Lin and Hsieh (2014) predict and pinpoint the flow pattern, airflow rate, efficiency, and noise for ceiling fans with different design parameters using numerical and experimental techniques. The study reports that for an inadequate housing, 'inhale-return' phenomenon can occur that affects the performance and power consumption of aceiling fan because its inlet and outletarealmost located at the same plane.

Afaq and Maqsood et al.(2014), Adeeb and Maqsood et al. (2015) and Adeeb and Maqsood et al. (2015) have done blade parametric studies and investigated the effect of number of blades on ceiling fan performance respectively. Results of improvement in air delivery, mass flow rate and service value of Commercial of the Shelf (COTS) ceiling fans by modifying blade geometry are reported. The parameters considered for design improvement are rake angles; root and tip bent angles and positions.

Aziz and Shahat et al. (2012) experimentally and numerically investigated the behavior of ceiling fan induced flow field inside a ventilated room and observed the effects of vortices, round and square ceiling diffuser on thermal comfort. Results show that energy saved by square or round diffuser is 1.5 times greater than vortex diffuser.

Rizk and El-Deberky et al. (2015) studied computationally and mathematically effect of ceiling and wall on air temperature during night in extremely hot climates. During night, indoor temperature of the building is high due to gain of heat and the indoor temperature is going beyond thermal comfort.

Nawaz and Kanti et al. (2012) established a fuzzy inference system that controls Revolutions per minute (rpm) of ceiling fan according to temperature of environment and relative humidity. For validation, experimental data is compared with different mathematical procedures. Using fuzzy logic toolbox they developed a simulation scheme to investigate the 
result. Amano and Lee et al. (2005) studied experimental and CFD/FEA simulation of large axial fan effect on flow. The flow pattern is changed by adding a radiator in front of axial fan. However, it produces around 10 to 20 percent stresses on the blade surface. Ho and Rosario et al. (2005) made an effort to find the best thermal comfort level with the combination of air-conditioners and ceiling fans. A two dimensional steady state problem was solved using CFD simulation. Fourteen different simulation cases were run for different locations of inlet diffuser and the position of the fan.

Momoi and Sagara et al. (2004) studied the velocity profile of a ceiling fan in an air-conditioned room. CFD results show greater value of velocity profile near the rotational centre of the ceiling fan. Lin and Hsieh et al. (2013) developed a new approach for installation of ceiling fans that have an enclosed housing and is hidden inside the ceiling floor. Using experimental and numerical methodology, the flow behaviour is predicted with different operating conditions and geometric housing. Conclusions revealed that as air moves towards the floor, different flow patterns are generated and demonstrate "inhalereturn" phenomenon only when housing comprises of anomalous shaped high ring-plate and outlet-inlet ratio.

Prabhakaran and Kumar (2012) experimentally compared the composite materials fan blades with aluminum fan blades. Results show that composite blade save $34 \%$ fabrication cost and $30 \%$ power because of $28 \%$ weight reduction. Lubliner and Douglass et al. (2004) made an effort to make a solar powered ceiling fan which is cost effective and environment friendly. A comparative study is done between three and four blade ceiling fan and the results show little difference between velocity profile and RPM. Four blade ceiling fan should be used for better air circulation and three blades for energy efficiency.

Idahosa and Golubev et al. (2008) focused on Multidisciplinary Design Optimization (MDO) to make an

A ceiling fan consists of a hub, electric motor, 6 blades and the whole assembly is mounted to the ceiling of the room. An electric motor converts electrical energy to mechanical energy and spin the blades at desired rpm. The main purpose of the hub is optimized design of a fan blade using CFD. Three prototypes of fan models achieved $11 \%, 13.85 \%$ and $11.61 \%$ respectively.

E. Adeeb, A. Maqsood, A. Musthaq and C. H. SohnStudied the nonlinear (elliptical) plan form shape of blade in conjunction with blade tip width, root and tip angle of attack. The flow field is studied and the fan surface is modeled using ReynoldsAveraged-Navier-Stokes approach. By applying Design of Experiments (DOE), 16 experiments are designed for three blade ceiling fan using $2 \mathrm{k}$ factorial model. A multi-objective optimization problem is formulated with three performance variables; volumetric flow rate, torque and energy efficiency.

Comparisons between these 16 blades are done by using Response Surface Method (RSM) and subsequently an optimized design is proposed. The research reveals that the interactions between the design variables play a significant role in determining the performance. The tip angle of attack is found to be most important and influential. Moreover, the nonlinear forward sweep has a moderate effect on response parameters.

Until now investigation have been primarily conducted on the fan whose blades are rotating in a single plane but this study develop fundamental understanding of air flow phenomenon for double plane blade ceiling fan placed inside the close room. Double plane blade ceiling fan consist of 6 blades in a manner that 3 blades are arranged as conventional ceiling fan and remaining are arranged just below that 3 blades. A non-linear blade design and room dimensions are selected from Adeeb et al. [7]. The objective of the research is to compare the conventional ceiling fan and newly design ceiling fan with the help of experiment and optimize the design of the double plane blade ceiling fan with high air flow rate with less electricity consumption is the main purpose.

\section{II- PROBLEM FORMULATION AND METHODS}

to house the electric motor and hold the blades at specific angles.. A 56" (1.4224 m) diameter commercially available fan is utilized as a benchmark design in this study (Fig. 1). 
The diameter is based on the calculated circular area swept by the ceiling fan during operation. Ceiling fan blades are made of aluminum with a thickness of about $0.001 \mathrm{~m}$ spans $0.548 \mathrm{~m}$, three blades are 120 degree apart from one another and difference between two planes of blade is $25 \mathrm{~mm}$. The part of the blade which is attached to the hub is called root while the other is tip. The blade part which makes first contact with air is called leading edge and other part after which air rejoins is referred as trailing edge.

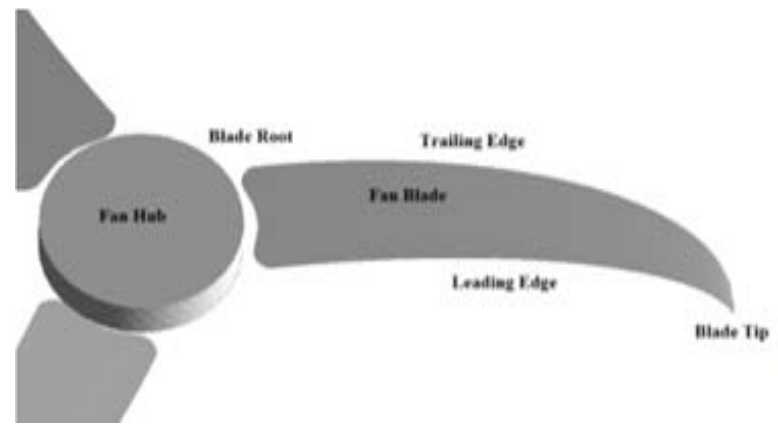

Fig1- Computational model of fan blade

\section{III- EXPERIMENTAL SETUP AND DATA}

\section{Collection}

Experiments are carried out in a test facility consisting of a square wooden room with dimension of $6.5 \mathrm{~m}$ in length and width and $3.5 \mathrm{~m}$ height which is shown in computational model in figure below. Ceiling fan is installed in a duct $1 \mathrm{~m}$ below the ceiling whose diameter is $1.56 \mathrm{~m}$.

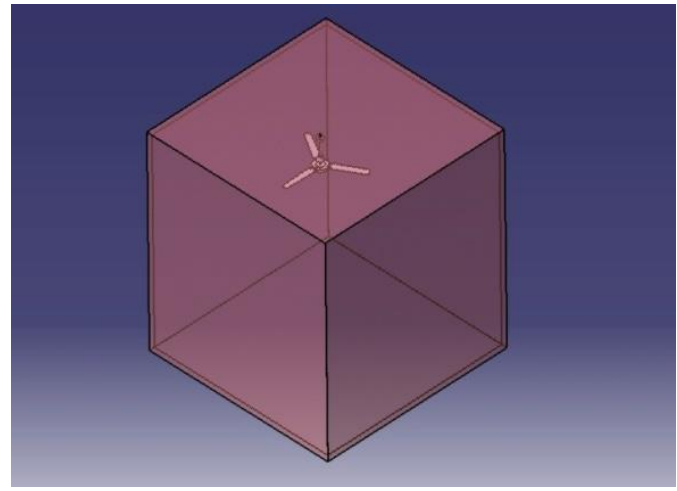

Fig.2.Ceiling Fan Room Model
Fan height from the ground is $2.5 \mathrm{~m}$. A tachometeris arranged as shown fig. 3 to measure the rotational motion in Revolutions per Minute (rpm). Entire controlling instruments and multicenter are installed on the wall. Electronic instruments showed readings in real time. Duct and controlling instruments are shown in Fig. 3. Air velocity is measured from hub to tip towards the wall with vane anemometer according to the stations shown in fig.3. Station dimension are given in table 3 .

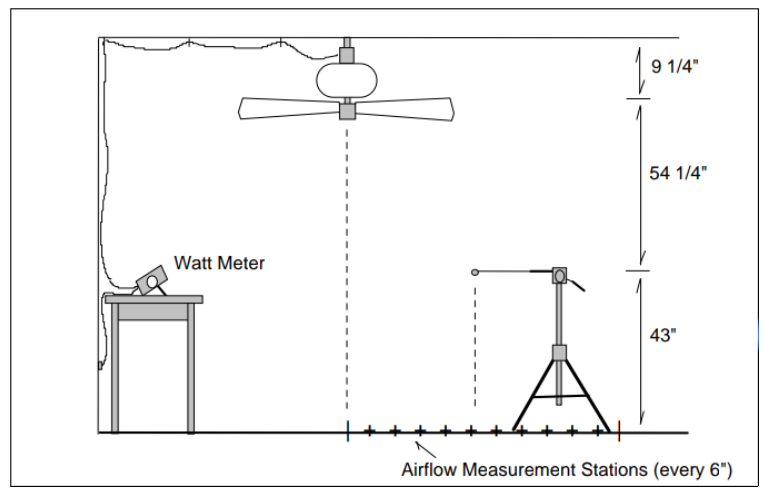

Fig.3.Test lab experiment set up

12 design of fan are considered for experiment with the changes in arrangements. As there are 6 blades which are positioned directly one above the other three upper blades and remaining 3 lower blades as shown fig. below.

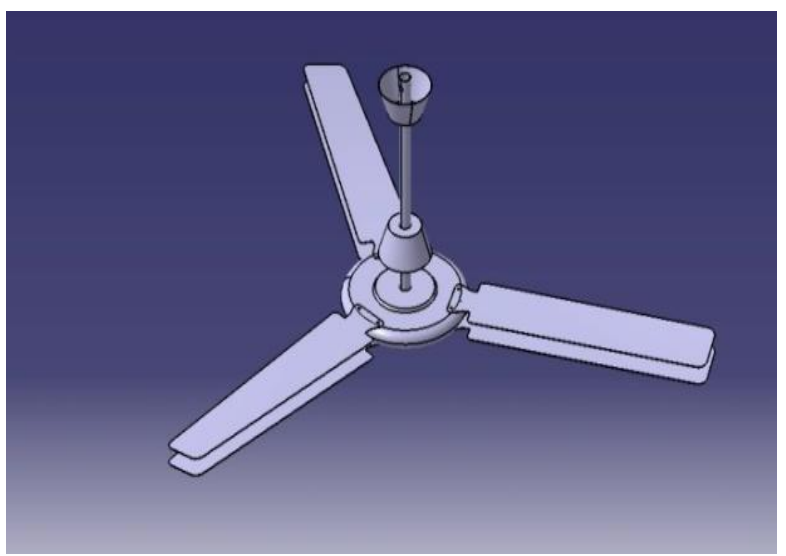

Fig.4; Model of double plane blade ceiling fan 


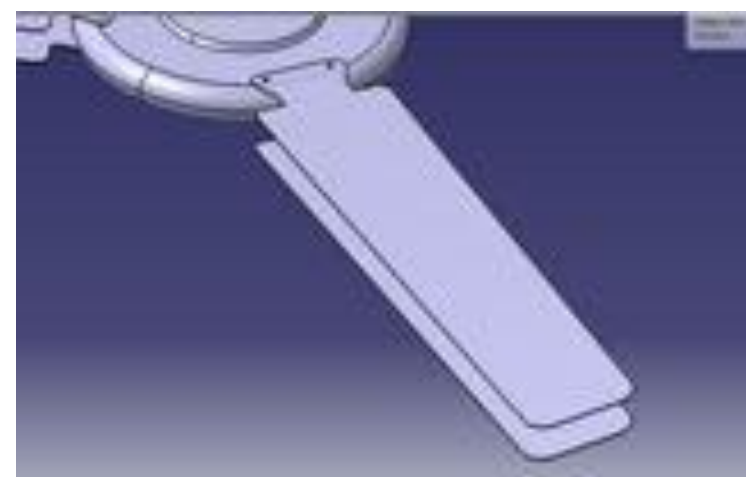

Fig.5; Close look of double plane blade ceiling fan

The lower blade dimensions are (Tip AOA 10 deg., root AOA 10deg., tip width $12 \mathrm{~mm}$ and Root width $26 \mathrm{~mm}$ ) are kept constant through all the process. But for the upper blade dimension changes step by step like AOA changes from 10 to 15 \& stagger (Moving of upper blade forward relative to the lower one) 10 to $20 \mathrm{~mm}$. With respect to all changes in AOA and stagger reading are recorded as in the following tables.
For each reading vane anemometer is placed for two minutes on the desired position before capturing the maximum velocity. The ceiling fan is switched for two hours before starting the experiment so the flow can be fully developed in the testing facility. Vane anemometer took eight readings according to station for each design changes. Further calculations are done by taking the average of these points. All points are calculated $1.5 \mathrm{~m}$ below the ceiling fan. Air velocity for experimental case is tabulated in Table 3 .

Table 6 -air flow stations distances

\begin{tabular}{|l|l|l|}
\hline Reading & $\begin{array}{l}\text { Airflow } \\
\text { measuring } \\
\text { station }\end{array}$ & $\begin{array}{l}\text { Distance (Hub to } \\
\text { Tip) (mm) }\end{array}$ \\
\hline 1 & A & 690 \\
\hline 2 & B & 575 \\
\hline 3 & C & 460 \\
\hline 4 & D & 345 \\
\hline 5 & E & 230 \\
\hline 6 & F & 115 \\
\hline 7 & G & 000 \\
\hline
\end{tabular}

Table 2- Experimentally measured air velocities for single plane blade fan

\begin{tabular}{|c|c|c|c|c|c|c|c|c|c|c|c|}
\hline \multirow[t]{2}{*}{ Reading } & \multirow[t]{2}{*}{ Speed (rpm) } & \multirow{2}{*}{$\begin{array}{c}\text { Lower } \\
\text { Blade } \\
\text { AOA(deg) }\end{array}$} & \multirow{2}{*}{$\begin{array}{c}\text { Upper } \\
\text { Blade } \\
\text { AOA(deg) }\end{array}$} & \multicolumn{7}{|c|}{ Velocities $(\mathrm{m} / \mathrm{s})$} & \multirow{2}{*}{$\begin{array}{c}\text { Mean } \\
\text { Velocity } \\
(\mathrm{m} / \mathrm{s})\end{array}$} \\
\hline & & & & A & B & C & $\mathrm{D}$ & $E$ & $\mathrm{~F}$ & $\mathrm{G}$ & \\
\hline 1 & 200 & 10 & 10 & 0.8 & 1.6 & 2 & 2.2 & 2.0 & 1.9 & 1.7 & 1.74 \\
\hline 2 & 200 & 10 & 12 & 1.4 & 1.9 & 2.3 & 2.3 & 1.7 & 1.7 & 1.8 & 1.87 \\
\hline 3 & 200 & 10 & 14 & 2 & 2.3 & 2.3 & 2.2 & 2.1 & 1.8 & 1.7 & 2.0 \\
\hline 4 & 200 & 10 & 15 & 1.7 & 2.4 & 2.2 & 2.1 & 1.7 & 1.5 & 1.7 & 1.9 \\
\hline
\end{tabular}

Table 3- Experimental measured air velocities for Double plane blade fan

\begin{tabular}{|c|c|c|c|c|c|c|c|c|c|c|c|c|}
\hline \multirow[t]{2}{*}{ Reading } & \multirow{2}{*}{$\begin{array}{l}\text { Stagger } \\
(\mathrm{mm})\end{array}$} & \multirow{2}{*}{$\begin{array}{l}\text { Speed } \\
\text { (rpm) }\end{array}$} & \multirow{2}{*}{$\begin{array}{l}\text { Lower } \\
\text { Blade } \\
\text { AOA(deg) }\end{array}$} & \multirow{2}{*}{$\begin{array}{l}\text { Upper } \\
\text { Blade } \\
\text { AOA(deg) }\end{array}$} & \multicolumn{7}{|c|}{ Velocities $(\mathrm{m} / \mathrm{s})$} & \multirow{2}{*}{$\begin{array}{l}\text { Mean } \\
\text { Velocity } \\
\text { (m/s) }\end{array}$} \\
\hline & & & & & $A$ & $B$ & C & $\mathrm{D}$ & $\mathrm{E}$ & $\mathrm{F}$ & $\mathrm{G}$ & \\
\hline 5 & 10 & 200 & 10 & 10 & 1.5 & 1.9 & 2 & 2 & 1.9 & 1.6 & 1.6 & 1.785 \\
\hline 6 & 10 & 200 & 10 & 12 & 1.3 & 1.6 & 1.9 & 1.9 & 1.7 & 1.7 & 1.6 & 1.671 \\
\hline 7 & 10 & 200 & 10 & 14 & 1.2 & 2 & 1.9 & 2 & 1.6 & 1.7 & 1.5 & 1.7 \\
\hline 8 & 10 & 200 & 10 & 15 & 1.1 & 1.8 & 2.1 & 2.2 & 2 & 1.6 & 1.5 & 1.75 \\
\hline 9 & 20 & 200 & 10 & 10 & 1.3 & 1.3 & 1.9 & 2.0 & 2.0 & 1.5 & 1.8 & 1.68 \\
\hline 10 & 20 & 200 & 10 & 12 & 1.3 & 1.6 & 1.9 & 2.1 & 1.9 & 1.7 & 1.6 & 1.728 \\
\hline 11 & 20 & 200 & 10 & 14 & 1 & 1.8 & 2 & 2.1 & 2 & 1.7 & 1.6 & 1.742 \\
\hline 12 & 20 & 200 & 10 & 15 & 1.4 & 1.8 & 2 & 2 & 2 & 1.7 & 1.5 & 1.77 \\
\hline
\end{tabular}




\section{IV- VALIDATION STUDIES}

\subsection{Generation of Design Space}

In this study, a total of three design variables are selected for study. These variables are Stagger, Lower Blade AOA (deg) and Upper Blade AOA (deg). Each variable has two levels, high and low. The selection of bounds is based on packaging and fabrication constraints. The range of three design variables and response parameters are shown in Table 3.

Volumetric flow rate is measured in the form of air delivery. It is defined as volumetric rate of change of air per unit time. Velocity is measured $1.5 \mathrm{~m}$ below the ceiling fan experimentally.
Torque is the tendency of a force to rotate an object about an axis. Energy efficiency is ratio of volumetric flow rate to torque and its unit is $\mathrm{m} 2 / \mathrm{min}$. N.

There are total three variables and each factor associated with two levels makes 12 experiments through full factorial design model. These blades are computationally designed with a combination of these parameters. The 12 combinations of design variables with different levels result in the development of design matrix as represented in Table 3and 4.

Table 4- Calculation of volumetric flow rate, torque, energy Efficiency

\begin{tabular}{|c|c|c|c|}
\hline \multirow[b]{2}{*}{ Design no. } & \multicolumn{3}{|c|}{ Result } \\
\hline & $\begin{array}{c}\text { Volumetric } \\
\text { Flow Rate } \\
\text { (m3/min) }\end{array}$ & $\begin{array}{l}\text { Torque } \\
\text { (N. m) }\end{array}$ & $\begin{array}{c}\text { Energy } \\
\text { Efficiency } \\
\text { (m2/N.min) }\end{array}$ \\
\hline 1 & 97.9 & 0.56 & 174 \\
\hline 2 & 102.3 & 0.61 & 166 \\
\hline 3 & 125.3 & 0.78 & 158 \\
\hline 4 & 129.4 & 0.86 & 149 \\
\hline 5 & 116.3 & 1.02 & 113 \\
\hline 6 & 133.7 & 1.09 & 121 \\
\hline 7 & 170.3 & 1.43 & 118 \\
\hline 8 & 174 & 1.66 & 104 \\
\hline 9 & 101 & 0.62 & 162 \\
\hline 10 & 105 & 0.68 & 114 \\
\hline 11 & 128 & 0.86 & 149 \\
\hline 12 & 130 & 0.9 & 144 \\
\hline 13 & 133 & 1.15 & 115 \\
\hline 14 & 138 & 1.34 & 102 \\
\hline 15 & 170 & 1.59 & 106 \\
\hline 16 & 185 & 1.76 & 104 \\
\hline
\end{tabular}




\section{V- RESULT AND DISCUSSION}

. The velocity profiles of all designed experiments are shown in Fig. 7 and Fig. 8. A consistent behavior is detected for all blades that the velocity is higher around $0.2-0.5 \mathrm{~m}$ and significantly decreases towards the blade tip. The velocity near the blade tip is less due to formation of tip vortices. The maximum velocity is achieved near hub and starts decreasing gradually and shows minimum values near the blade tip.
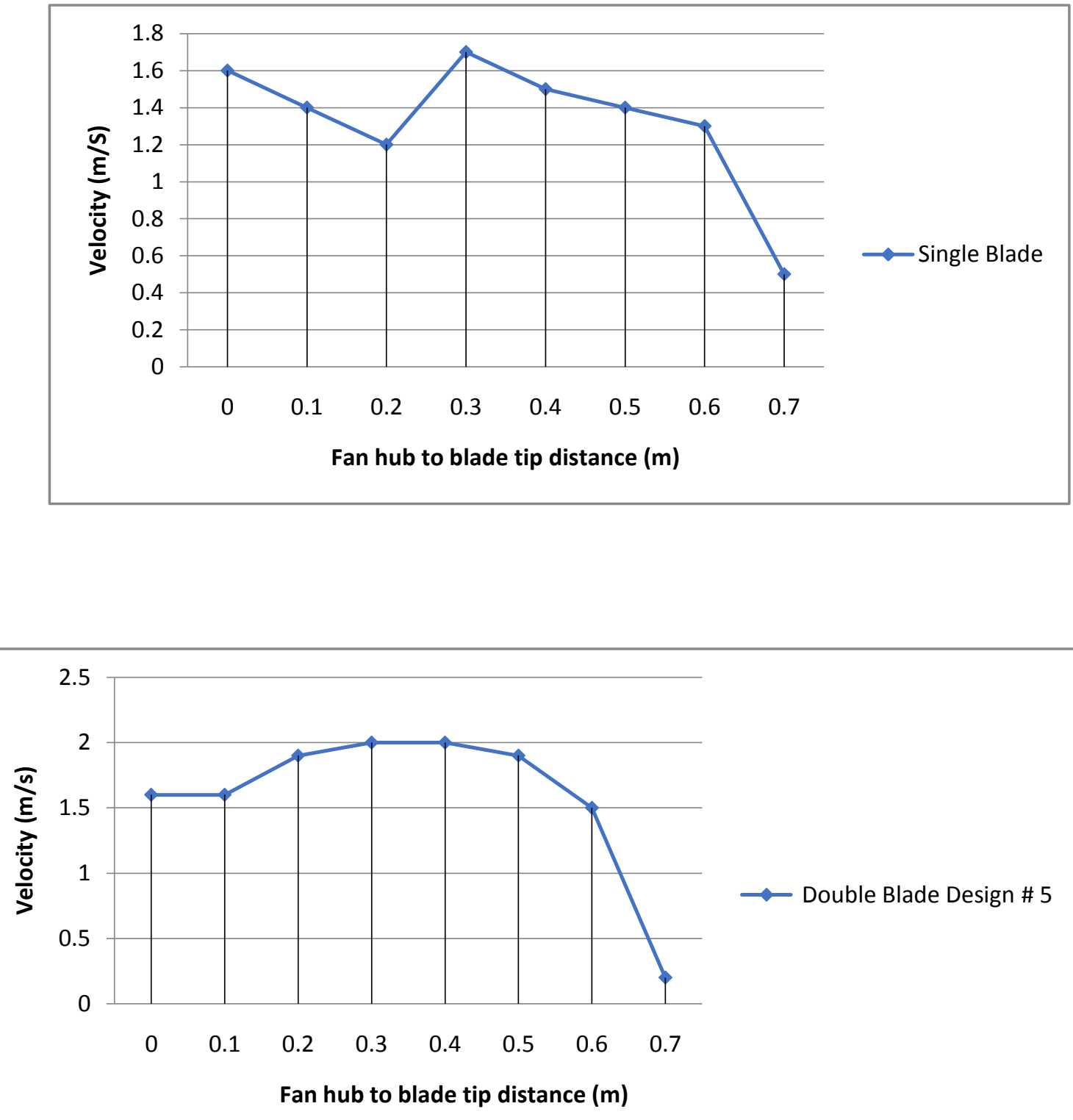
Blade number 5 shows the maximum velocity below $1.5 \mathrm{~m}$ of the ceiling fan. It should be noted that the blade no $10,11,12$ which are having high values of the geometric parameters are possesses the velocity

\section{V- CONCLUSION}

In this work, a comparative study is carried out between the three blade ceiling fan and newly design double plane 6 blade ceiling fan. There are 12 design of ceiling fans based on the variables depends on stagger and AOA which are experimented and shown

\section{REFERENCES}

[1] Adeeb, E., A. Maqsood and A. Mushtaq (2015). Effect of Number of Blades on Performance of Ceiling Fans. 4th International Conference on Advances in Mechanics Engineering, Spain, MATEC Web of Conferences.

[2] Adeeb, E., A. Maqsood, A. Mushtaq and Z. Hussain (2015). Shape Optimization of non-linear swept ceiling fan blades through RANS simulations and Response Surface Methods. 12th International Bhurban Conference on Applied Sciences and Technology, IEEE.

[3] Afaq, M. A., A. Maqsood, K. Parvez and A. Mushtaq (2014). Study on the design improvement of an indoor ceiling fan. 11th International Bhurban Conference on Applied Sciences and Technology, IEEE.

[4] Amano, R. S., E. K. Lee, C. Xu and J. Xie (2005). Investigation of the Unsteady Flow Generated by an Axial Fan: Experimental Testing and Simulations. International Journal of Rotating Machinery 3, 256-263.

[5] Ankur, J., R. U. Rochan, C. Samarth, S. Manish and K. Sunil (2004). Experimental Investigation of the Flow Field of a Ceiling Fan. ASME 2004 Heat Transfer/Fluid Engineering Summer Conference, Charlotte, North Carolinia, USA.

[6] Azim, M. A. (2014). Velocity field analysis of a ceiling fan. Turkish Journal of Engineering, Science and Technology 01, 1-7. Aziz, M. A., I. A. M. G. close to the design 5. By comparing the above graphs is seen that the air velocity for conventional fan is hard to predict as compare to double plane blade ceiling fan.

in fig 4 in the terms of Volume flow rate, torque and energy Efficiency. It is observed that mass and volumetric flow rates are maximum for fifth design (i.e. design 5) therefore configuration of design number 5 are more desirable.

Shahat, F. A. Mohammed and R. H. Mohammed (2012). Experimental and numerical study of influence of air ceiling diffusers on room air flow characteristics. Energy and Buildings 55, 738-746.

[7] Bhortake, R. V., P. S. Lachure, S. R. Godase, V. V. More and K. S. Chopade (2014). "Experimental Analysis of Air Delivery in Ceiling Fan." International Journal of Emerging Technology and Advanced Engineering 4(6), 247-251.

[8] Chiang, H.C., C.S. Pan, H. S. Wu and B. C. Yang (2007). Measurement of Flow Characteristics of a Ceiling Fan with Varying Rotational Speed. In Proceedings of Clima 2007 WellBeing Indoors.

[9] Falahat, A. (2011). "Numerical and Experimental Optimization of Flow Coefficient in Tubeaxial Fan." International Journal of Multidisciplinary Sciences and Engineering 2(5), 24-29.

[10] Ho, S. H., L. Rosario and M. M. Rahman (2005, August). Effect of using ceiling fan on human thermal comfort in Air-conditioned space. In Proceedings of 3rd International Energy Conversation Engineering Conference, San Francisco, California

[11] Prabhakaran, $S$. and $M . \quad S$. Kumar (2012).Development of Glass Fiber Reinforced Polymer Composite Ceiling Fan Blade. International Journal of Engineering Research and Development 2(3), 59-64.

[12] Ramadan, B. and S. K. Nadar (2011). "Studying the Features of Air Flow Induced by a Room CeilingFan." Energy and Buildings 43(8), 1913-1918. 
[13] Rizk, A., A. El-Deberky and N. Guirguis, M (2015).Simulation Comparison Between Natural and Hybrid Ventilation by Fans at Nighttime for Severe Hot Climate (Aswan, Egypt). Renewable Energy in the Service of Mankind 1(1) 609-620

[14] Sathaye, N., A. Phadke, N. Shah and V. Letschert(2012). Potential Global Benefits of Improved Ceiling Fan Energy Efficiency. LBNL Report Ernest Orlando Lawrence Berkeley National Laboratory, United States Schiavon, S. and A. K. Melikov (2008). Energy saving and improved comfort by increased air movement. Energy and Buildings 40(10), 1954-1960.

[15] Schmdit, K. and D. J. Patterson (2001). Performanceresult for a high efficiency tropical ceiling fanand comparisons with conventionalfansdemand side management via smallappliance efficiency. Renewable energy 22(3), 169-176.

[16] Singh, O. P., M. Garg, V. Kumar and $Y$. V.Chaudhary (2013). Effect of Cooling System Design on Engine Oil Temperature. Journal of Applied Fluid Mechanics 6(1), 61-71.

[17] Sivakumar, V. M., A. Surendhar and T. Kannadas an(2015). Prediction of Air Flow and Temperature Distribution Inside a Yogurt Cooling Room Using Computational Fluid Dynamics. Journal of Applied Fluid Mechanics8(2), 197-206.

[18] Spalart, P. R. a. A., S. R. (1992). A One-Equation Turbulence Model for Aerodynamic Flows. In Proceedings of Aerospace Sciences Meeting and Tripathi, B. and S. G. Moulic (2012). Investigation of Air Drafting Pattern Obtained from the Variation in Outlet Positions inside a Closed Area. Journal of Applied Fluid Mechanics 5(4), 1-12. 